\title{
Análise da distribuição de forças resultantes de contato oclusal prematuro entre primeiros pré-molares: Um estudo 3D de elementos finitos
}

\author{
Analysis of the distribution of forces resulting from premature occlusal contact between first \\ premolars: A 3D finite element study \\ Análisis de la distribución de fuerzas resultantes del contacto oclusal prematuro entre los primeros \\ premolares: un estudio de elementos finitos en 3D
}

Recebido: 28/08/2021 | Revisado: 05/09/2021 | Aceito: 08/09/2021 | Publicado: 09/09/2021

\author{
Daisilene Baena Castillo \\ ORCID: https://orcid.org/0000-0003-4261-7503 \\ Universidade Federal de Mato Grosso do Sul, Brasil \\ E-mail: daisilene@hotmail.com \\ Victor Augusto Alves Bento \\ ORCID: https://orcid.org/0000-0003-0558-4239 \\ Universidade Estadual Paulista Júlio de Mesquita Filho, Brasil \\ E-mail: vtrbento97@gmail.com \\ Jànes Landre Júnior \\ ORCID: https://orcid.org/0000-0001-6640-3601 \\ Pontifícia Universidade Católica de Minas Gerais, Brasil \\ E-mail: daisilene@hotmail.com \\ Paulo Isaías Seraidarian \\ ORCID: https://orcid.org/0000-0003-4274-7340 \\ Pontifícia Universidade Católica de Minas Gerais, Brasil \\ E-mail: seraidarian@gmail.com
}

\begin{abstract}
Resumo
Os contatos oclusais são considerados um dos fatores mais importantes no sucesso do tratamento odontológico, pois as interferências oclusais podem implicar em danos potenciais a todo o sistema estomatognático. Os aspectos dos eventos biomecânicos que resultam de contatos prematuros oclusais sobre os dentes e seus tecidos de suporte, ainda não estão suficientemente esclarecidos. Assim, o objetivo deste estudo foi avaliar, por meio do método de elementos finitos tridimensional, a distribuição das tensões, nos dentes e tecidos de sustentação, geradas por diferentes contatos prematuros em primeiro pré-molar superior e inferior, na posição de oclusão cêntrica. A pesquisa foi delineada considerando dois fatores de contatos prematuros possíveis de ocorrer clinicamente, contato "A" e contato "B". Foi gerado malhas através do software Solidworks ${ }^{\circledR}$ e os testes foram realizados pelo software de elementos finitos Cosmos Design Star, com intensidade da carga de $100 \mathrm{~N}$ na face oclusal. Mapas de von Mises foram gerados para análise de distribuição de tensão no dente, no alvéolo, e no conjunto dente e alvéolo. Maiores tensões foram observadas na junção amelocementária dos pré-molares superiores em contato "A" (12,34 Mpa) e "B" (13,56 Mp), enquanto que em relação ao conjunto dente e alvéolo maiores tensões se encontravam na hemi-arcada inferior em contato "A" (11,02 Mpa) e "B" (10,53 Mpa). Conclui-se que tanto no contato prematuro em "A", quanto em "B", ocorre sempre a concentração da tensão máxima em torno do limite amelocementário, seja no primeiro pré-molar superior ou no primeiro pré-molar inferior.
\end{abstract}

Palavras-chave: Oclusão dentária; Sistema estomatognático; Análise de elementos finitos.

\begin{abstract}
Occlusal contacts are considered one of the most important factors in the success of dental treatment, as occlusal interferences can result in potential damage to the entire stomatognathic system. The aspects of biomechanical events that result from premature occlusal contacts on teeth and their supporting tissues are still not sufficiently clear. Thus, the aim of this study was to evaluate, using the three-dimensional finite element method, the distribution of stresses, in teeth and supporting tissues, generated by different premature contacts in upper and lower first premolars, in the centric occlusion position. The research was designed considering two factors of premature contacts that are possible to occur clinically, "A" contact and "B" contact. Meshes were generated using the Solidworks ${ }^{\circledR}$ software and the tests were performed using the finite element software Cosmos Design Star, with a load intensity of $100 \mathrm{~N}$ on the occlusal surface. Von Mises maps were generated to analyze the stress distribution in the tooth, in the socket, and in the set of tooth and socket. Higher tensions were observed at the cemento-enamel junction of the maxillary premolars in contact "A" (12.34 Mpa) and "B" (13.56 Mp), while in relation to the tooth and alveolus set, higher tensions were found in the hemi- lower arch in "A" (11.02 Mpa) and "B" (10.53 Mpa) contact. It is concluded that both in premature contact
\end{abstract}


in "A" and in "B", there is always the concentration of maximum tension around the cementoenamel limit, either in the maxillary first premolar or in the mandibular first premolar.

Keywords: Dental occlusion; Stomatognathic system; Finite element analysis.

\section{Resumen}

Los contactos oclusales se consideran uno de los factores más importantes para el éxito del tratamiento dental, ya que las interferencias oclusales pueden provocar daños potenciales en todo el sistema estomatognático. Los aspectos de los eventos biomecánicos que resultan de contactos oclusales prematuros en los dientes y sus tejidos de soporte aún no están lo suficientemente claros. Así, el objetivo de este estudio fue evaluar, utilizando el método de elementos finitos tridimensionales, la distribución de tensiones, en dientes y tejidos de soporte, generadas por diferentes contactos prematuros en primeros premolares superiores e inferiores, en la posición de oclusión céntrica. La investigación se diseñó considerando dos factores de contactos prematuros que pueden ocurrir clínicamente, el contacto "A" y el contacto "B". Las mallas se generaron con el software Solidworks® y las pruebas se realizaron con el software de elementos finitos Cosmos Design Star, con una intensidad de carga de $100 \mathrm{~N}$ en la cara oclusal. Se generaron mapas de Von Mises para analizar la distribución de la tensión en el diente, en el alveolo y en el juego de diente y alveolo. Se observaron mayores tensiones en la unión cemento-esmalte de los premolares superiores en contacto "A" (12,34 Mpa) y "B" (13,56 Mp), mientras que en relación al conjunto dentario y alvéolo, se encontraron mayores tensiones en los hemi- arco inferior en contacto "A" (11.02 Mpa) y "B" (10.53 Mpa). Se concluye que tanto en el contacto prematuro en "A" como en "B", siempre existe la concentración de tensión máxima alrededor del límite amelocementario, ya sea en el primer premolar maxilar o en el primer premolar mandibular.

Palabras clave: Oclusión dental; Sistema estomatognático; Análisis de elementos finitos.

\section{Introdução}

Os contatos oclusais são considerados um dos fatores mais importantes no sucesso do tratamento odontológico, pois as interferências oclusais podem implicar em danos potenciais a todo o sistema estomatognático, que inclui dentes, estruturas de suporte, sistema neuromuscular e articulações temporomandibulares (Brandini et al, 2012; Wang \& Yin 2012). O conhecimento desses danos motiva a comunidade científica a realizar estudos para melhor entendimento da distribuição de tensão gerado por diferentes contatos oclusais prematuros e seus efeitos nas estruturas do complexo craniofacial.

Os contatos prematuros em relação cêntrica ocorrem quando a mandíbula se fecha em uma posição fisiológica e é desviada para uma posição funcional onde ocorre o contato dentário máximo (Miller et al, 2003). Um deslizamento de relação cêntrica/oclusão cêntrica ocorre quando as superfícies de contato prematuro deslizam uma sobre a outra e os dentes se movem para a intercuspidação máxima, fazendo com que forças excêntricas sejam transmitidas através do dente para a área cervical e tecidos periodontais. O deslizamento ocorre quando há repetição do contato prematuro e, com intuito de proteger o elemento dental ou o periodonto, surge nova atividade reflexa que, através de estiramento ou contração de alguns músculos, desvia a mandíbula para uma nova posição, resultando na perda da sua estabilidade funcional original e desenvolvimento de uma oclusão habitual (Miller et al, 2003; Reyes et al, 2009).

Forças oclusais excessivas são associadas à flexão dentária, causando microfraturas mecânicas e perda de substância dentária na região cervical, apresentando um padrão característico de perda de substância dentária na junção cemento-esmalte (Correia et al, 2020). As forças mastigatórias aplicadas fora do eixo dentário longitudinal normalmente geram forças laterais que são dissipadas principalmente na junção amelocementária, consequentemente, o dente fica deformado e ocorrem desconexões entre os cristais de hidroxiapatita na área de tensão, resultando em microrrupturas. A ruptura cria espaços repletos de moléculas de água que impedem a formação de novas conexões químicas entre os cristais, tornando as estruturas cristalinas vulneráveis à ação química e às forças físicas geradas por processos fisiológicos ou mecânicos (Lim et al, 2020; Pai et al, 2020). Essa perda adicional da estrutura dentária muitas vezes resulta em lesões cervicais não cariosas (NCCLs), uma das principais causas da sensibilidade dentária (Medeiros et al, 2020; Correia et al, 2020).

Os aspectos dos eventos biomecânicos que resultam de contatos prematuros oclusais sobre os dentes e seus tecidos de suporte, ainda não estão suficientemente esclarecidos. Assim, avaliar os efeitos ao dente e tecido de sustentação da distribuição de tensão entre diferentes interferências oclusais podem contribuir para melhor compreensão. Entretanto, muitas vezes se torna 
inviável e de difícil entendimento realizar tais análises através de estudos in vivo ou in vitro (Yang et al, 2015). Como alternativa a análise dos elementos finitos pode ser útil para avaliar os resultados sobre as tensões, imitando as condições clínicas (El-Anwar et al, 2015).

Diante disso, o propósito deste estudo foi avaliar, por meio do método de elementos finitos tridimensional, a distribuição das tensões, nos dentes e tecidos de sustentação, geradas por diferentes contatos prematuros em primeiro prémolar superior e inferior, na posição de oclusão cêntrica.

\section{Metodologia}

\subsection{Desenho Experimental}

Essa pesquisa foi delineada considerando dois fatores de contatos prematuros possíveis de ocorrer clinicamente, sendo contato prematuro em contato "A" e contato "B" (Cerveira Netto e Zanatta,1998). O contato "A" é estabelecido entre a vertente triturante da cúspide de não-contenção do dente superior (vestibular) com a vertente lisa da cúspide de contenção do dente inferior (vestibular), enquanto o contato "B" é estabelecido entre a vertente triturante da cúspide de contenção do dente superior (palatina) com a vertente triturante da cúspide de contenção do dente inferior (vestibular) (Figura 1).

Figura 1: Localização do contato prematuro. A: Contato prematuro na vertente mésio-oclusal da cúspide vestibular do primeiro pré-molar superior esquerdo; B: Contato prematuro no segmento distal da aresta longitudinal da cúspide vestibular do primeiro pré-molar inferior esquerdo; C: Contato prematuro na vertente mésio-oclusal da cúspide palatina do primeiro prémolar superior esquerdo; D: Contato prematuro na vertente disto-oclusal da cúspide vestibular do primeiro pré-molar inferior esquerdo.

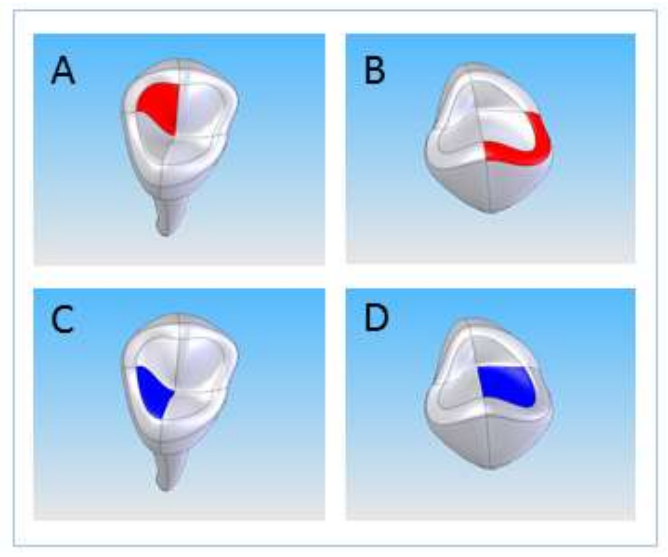

Fonte: Autores.

\subsection{Modelos}

Foram criados modelos computacionais representando os hemi-arcos esquerdos, superior e inferior, através do software Solidworks $®$. As malhas foram geradas de forma a reproduzir com fidelidade a geometria, sendo do tipo Standard Draft Mesh sólida com cerca de 436.197 nós e 312.485 elementos, cada modelo (Figura 2). 
Figura 2: Modelos Computacionais. A: Malha gerada do modelo superior; B: Malha gerada do modelo inferior.

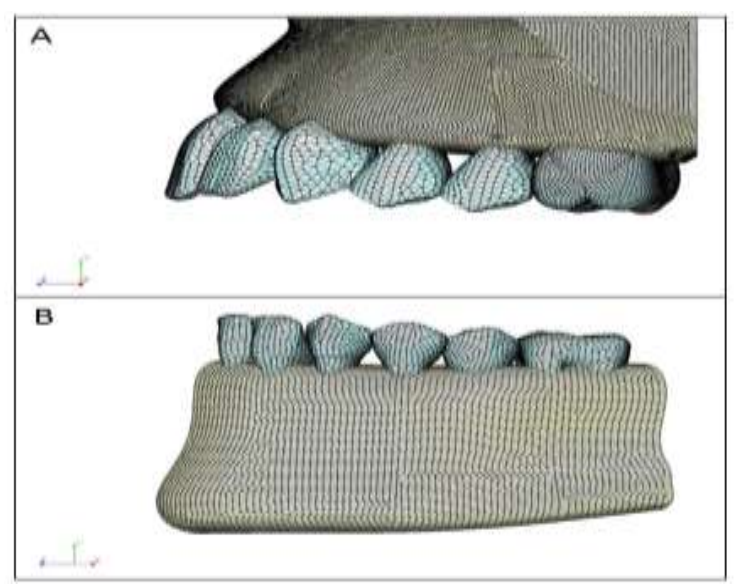

Fonte: Autores.

Todas as geometrias foram exportadas para o software de elementos finitos (Cosmos. Design Star, Structural Research and Analysis Corporation, USA), e neste, na fase de pré-processamento, as propriedades mecânicas de cada estrutura utilizada no estudo foram incorporadas e atribuídos os valores às malhas geradas, utilizando os valores extraídos da literatura (Tabela 1).

Tabela 1: Propriedade dos materiais.

\begin{tabular}{|c|c|c|c|c|}
\hline Estrutura & $\begin{array}{l}\text { Módulo de Elasticidade } \\
\text { (E) (GPa) }\end{array}$ & $\begin{array}{l}\text { Coeficiente } \\
\text { de Poisson (v) }\end{array}$ & $\begin{array}{l}\text { Densidade } \\
\left(\mathrm{g} / \mathrm{cm}^{3}\right)\end{array}$ & Referência \\
\hline $\begin{array}{l}\text { Dentes e Processo } \\
\text { Alveolar }\end{array}$ & 84,1 & 0,30 & 3,0 & Kohn (2004) \\
\hline $\begin{array}{l}\text { Tecido Ósseo } \\
\text { maxila e mandíbula }\end{array}$ & 18,0 & 0,33 & 0,7 & Kohn (2004) \\
\hline
\end{tabular}

Fonte: Autores.

Todos os materiais foram considerados isotrópicos, homogêneos e linearmente elásticos. Os contatos das estruturas foram considerados colados. As condições de contorno dos modelos foram estabelecidas como fixadas em todos os eixos (x, y e z), a fim de inibir os deslocamentos na região alveolar.

\subsection{Teste}

Os cálculos matemáticos de cargas e tensões foram realizados pelo software Cosmos Design Star (Structural Research and Analysis Corporation, USA). A carga foi aplicada na face oclusal de cada dente com intensidade da carga de $100 \mathrm{~N}$, simulando os contatos prematuros "A" e "B", conforme Rossi et al (2021). A análise de processamento dos modelos foi realizada em uma estação de trabalho HP (Hewlett-Packard Development Company, L.P., Palo Alto, California, USA), com as seguintes características: processador Intel ${ }^{\circledR}$ Xeon ${ }^{\circledR}$ x3470, 16 GB de RAM e 2 TB de HD. Desta forma, os resultados foram transferidos ao software Cosmos Design Star (Structural Research and Analysis Corporation, USA) para o pós-processamento e visualização gráfica das tensões através de mapas. 


\subsection{Análise dos dados}

Mapas de von Mises (TvM) foram utilizados para avaliar os primeiros pré-molares e tecido ósseo adjacente em diferentes tomadas de imagens (Tabela 2). As tomadas de imagens utilizadas no estudo são as posições que melhor expressam os resultados das estruturas avaliadas. A unidade de medida usada para mensurar a Tensão de von Mises foi Mega-Pascal (Mpa), utilizando escala de 0-100 Mpa.

Tabela 2: Diferentes tomadas de imagens utilizadas através de mapas de von Mises.

\begin{tabular}{|l|l|}
\hline ESTRUTURA ANATÔMICA & VISTA ANALISADA \\
\hline Dente & Oclusal, Mesial, Vestibular E Lingual \\
\hline Dente e Alvéolo & Vestibular E Lingual \\
\hline Alvéolo & Vestibular E Lingual \\
\hline
\end{tabular}

Fonte: Autores.

\section{Resultados}

\subsection{Tensão von Mises no dente}

No primeiro pré-molar superior o contato prematuro em "A" gerou uma tensão de 5,14 Mpa na face oclusal que se dissipou pela cúspide vestibular, concentrando-se no terço cervical da face vestibular próximo ao limite amelocementário, e uma tensão de 12,34 Mpa no terço cervical da raiz lingual, também próximo ao limite amelocementário. O contato prematuro em "B" gerou uma tensão de 5,65 Mpa na face oclusal que dissipou pela cúspide lingual, concentrando-se no terço cervical da face lingual chegando a 13,56 Mpa, enquanto que na face vestibular chegou a 6,78 Mpa. (Figura 3).

Figura 3: Tensão von Mises no primeiro pré-molar superior. A: contato prematuro em "A"; B: contato prematuro em "B".

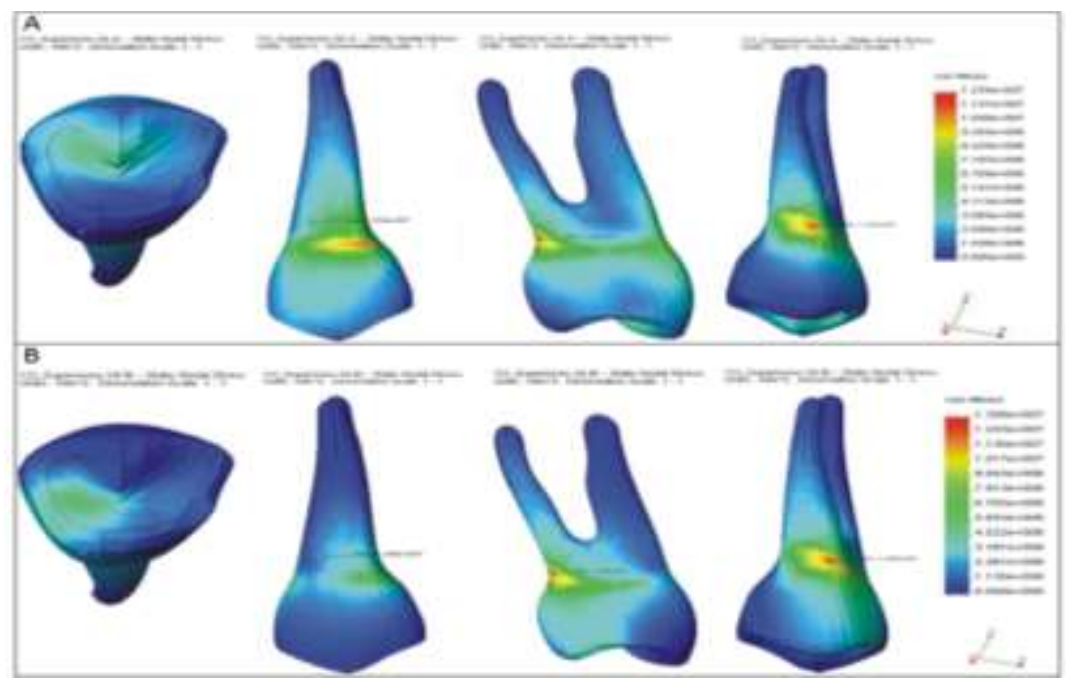

Fonte: Autores.

No primeiro pré-molar inferior o contato prematuro em "A" gerou uma tensão de 5,51 Mpa na crista marginal distal e metade distal da cúspide vestibular, concentrando-se na metade mesial do terço cervical da raiz, próximo ao limite amelocementário, atingindo o valor de 11,02 MPa. O contato prematuro em "B" gerou uma tensão de 7,01 Mpa na vertente disto-oclusal da cúspide vestibular, e concentração de tensão no limite amelocementário da face vestibular, com 14,04 MPa. $\mathrm{Na}$ face lingual observa-se que, assim como em "A", a cúspide lingual não é envolvida, porém, a concentração da tensão registrou maior representatividade no limite amelocementário (12,87 MPa). (Figura4). 
Figura 4: Tensão von Mises no primeiro pré-molar inferior. A: contato prematuro em "A"; B: contato prematuro em "B".

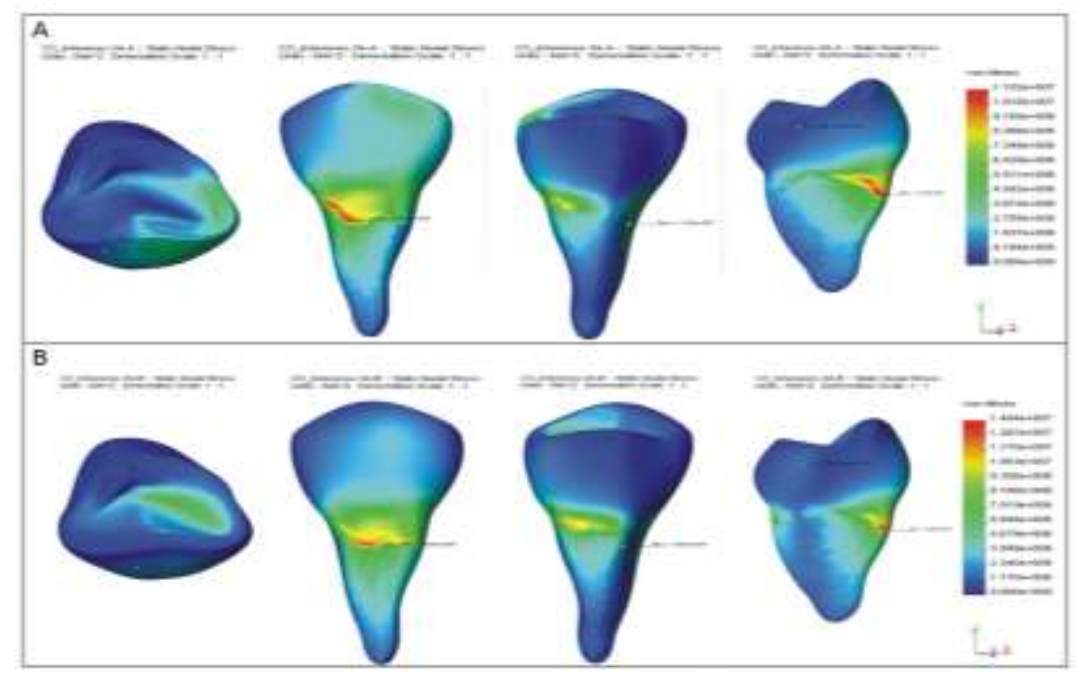

Fonte: Autores.

\subsection{Tensão von Mises no dente e alvéolo, e alvéolo}

O conjunto elemento dental e alvéolo do hemiarco superior, no contato em "A", observa-se que no dente a tensão é de 3,08 Mpa na maior parte da face vestibular, estendendo-se até as proximidades do vértice da cúspide e, no limite amelocementário, atinge a intensidade de 11,31 Mpa. A presença da tensão na tábua óssea vestibular é de 3,08 Mpa. No contato em "B", observa-se que, a tensão se localiza no terço cervical da face vestibular do dente, com discreta dissipação na tábua óssea vestibular do alvéolo. Na face lingual a máxima tensão posiciona-se na porção mésio-cervical do dente, indo um pouco além do limite amelocementária. Na vista oclusal do alvéolo, no contato em "B”, observa-se que a máxima tensão se localiza semelhantemente ao observado no contato em "A”, porém com menor intensidade. (Figura 5).

Figura 5: Tensão von Mises no conjunto elemento dental e alvéolo do hemiarco superior. A: contato prematuro em "A"; B: contato prematuro em "B".

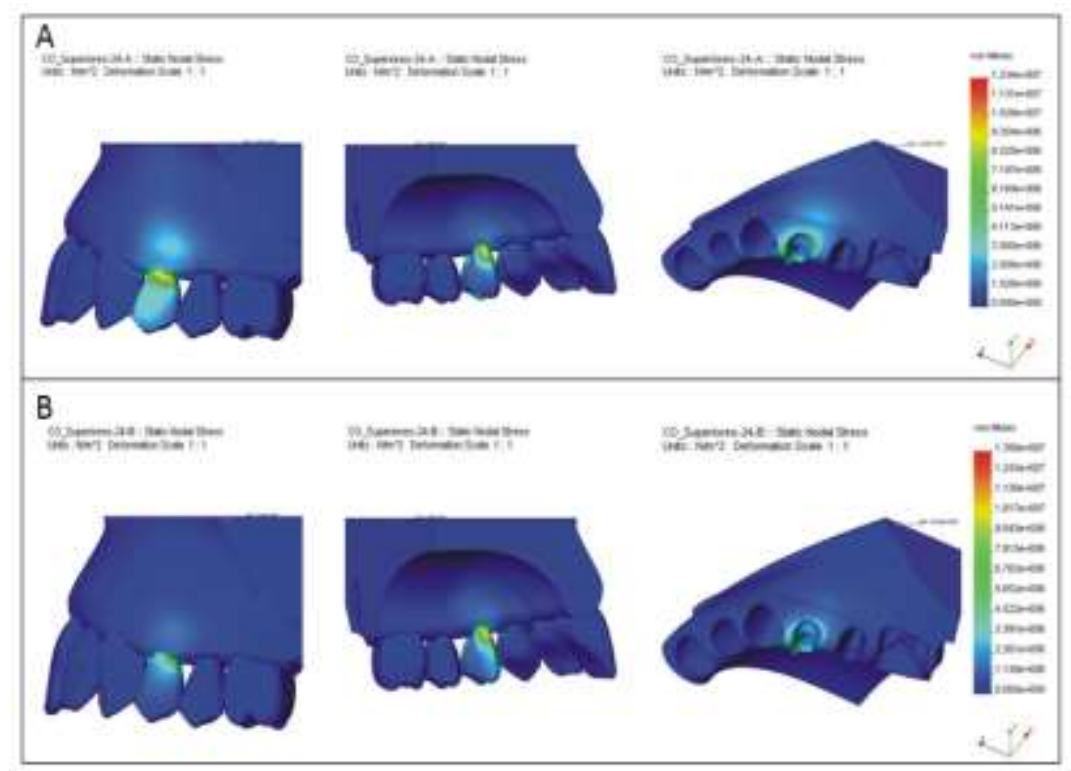

Fonte: Autores. 
O conjunto elemento dental e alvéolo do hemiarco inferior, no contato em "A", observa-se que a vértice da cúspide vestibular apresenta uma tensão de 6,42 MPa, que se dissipa na maior parte da face vestibular com valor médio de 6,75 Mpa, porém, no limite amelocementário, a tensão aumenta para 11,02 Mpa. Na face lingual a tensão restringe-se ao terço cervical no dente. No contato em "B", observa-se que a tensão, no dente, se apresenta em grande parte da face vestibular, estendendose, desde as proximidades do vértice da cúspide, até o limite amelocementário onde atinge a intensidade de 10,53 Mpa. Na vista lingual constata-se que a tensão se localiza na porção cervical, próximo ao limite amelocementário.

Figura 6: Tensão von Mises no conjunto elemento dental e alvéolo do hemiarco inferior. A: contato prematuro em "A"; B: contato prematuro em "B".

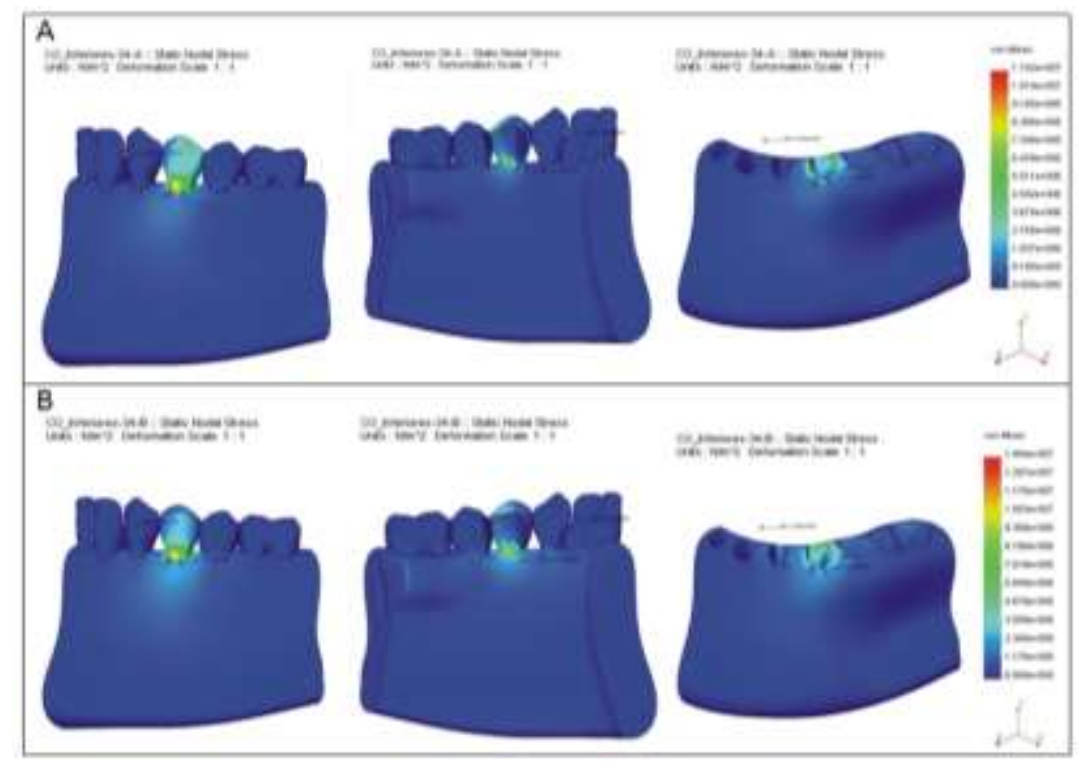

Fonte: Autores.

\section{Discussão}

Os resultados desta pesquisa reforçam, pelo método de elementos finitos, a importância da manutenção da morfologia oclusal, pois, qualquer alteração da mesma, tal como a presença de pontos de contato prematuro, gera resultante não axial de tensão, tanto na coroa como na raiz dental, chegando até ao alvéolo e as tábuas ósseas alveolares, vestibular e lingual.

$\mathrm{O}$ contato prematuro em "A" gera uma tensão que se dissipa pela cúspide vestibular, concentrando-se no terço cervical da face vestibular próximo ao limite amelocementário, onde atinge o seu maior valor. Tal constatação confirma a afirmação de Rossi et al. (2021), de que o estresse gerado na coroa clínica do dente pode provocar microfratura, fadiga e/ou flexão, abfração, no limite amelocementário. Confirma também os resultados de Dejak et al (2005), que constataram concentração de tensão no limite amelocementário, responsabilizando-a pela fratura do esmalte, e lesões cervicais do dente.

O contato prematuro em "B" gera uma tensão levemente maior que o contato prematuro em "A", e a dissipação da tensão fica às expensas da cúspide lingual e do terço cervical da raiz lingual, envolvendo a região da furca, concentrando-se próximo ao limite amelocementário. Esse resultado é compatível com o estudo de (Correia et al, 2020), segundo os quais, um toque não equilibrado, na superfície oclusal, gera tensão de forma oblíqua, que pode resultar em rompimento dos cristais de hidroxiapatita, formando as lesões cervicais não cariosas.

A análise dos efeitos do contato em "A" e "B", no conjunto dente/alvéolo do hemiarco superior apresentaram tensões que ultrapassaram o limite amelocementário, assim distribuindo-se na tábua óssea. Comprova-se assim, através do MEF, a afirmação de Reyes et al (2009), segundo a qual uma força anormal na superfície oclusal do dente poderá comprometer o 
periodonto, pois o contato prematuro gera uma força resultante não axial, concentrando a tensão na região de inserção do desmodonto, podendo ser um dos fatores a causar doenças periodontais.

No conjunto dente/alvéolo do hemi-arco inferior o contato prematuro em "A" dissipou para a crista marginal distal e metade distal da cúspide vestibular, estendendo-se, longitudinalmente, ao terço cérvico-vestibular da coroa e terço idêntico da raiz, e contato prematuro em "B" dissipou para metade vestibular da face mesial, abrangendo o terço médio da raiz, e concentrando-se no limite amelocementário das faces vestibular e lingual. Esses resultados corroboram com o estudo de Silva (2009), que demonstrou que a fratura de dentes posteriores, uma vez restaurados, resulta de contatos não equilibrados, do tipo "A" ou "B", por concentração indevida de tensão não desejada. Corroboram, também, os resultados de Lanza et al. (2005) que ao avaliarem fraturas do incisivo central superior (dente unirradicular, assim como o primeiro pré-molar inferior), concluíram que a maior tensão ocorre na face vestibular da raiz.

Quanto aos efeitos do contato prematuro em "A", verificou-se maior expressividade da tensão em quase todo o contorno da sua abertura, exceto no segmento disto-lingual e na tábua óssea vestibular. Como as tábuas ósseas do processo alveolar e a porção radicular do dente são vascularizadas e inervadas, a tensão gerada na região pode causar alteração dessas estruturas, o que justificaria a afirmativa de Medeiros et al, (2020), segundo os quais, um leve contato prematuro pode alterar a percepção do dente e causar dor.

\section{Conclusão}

A análise dos resultados obtidos nesta pesquisa, permite concluir que:

A) Tanto no contato prematuro em "A", quanto em "B", ocorre sempre a concentração da tensão máxima em torno do limite amelocementário, seja no primeiro pré-molar superior ou no primeiro pré-molar inferior.

B) O contato prematuro em "A" gera maior distribuição da tensão na cúspide vestibular do primeiro pré-molar inferior.

C) O contato prematuro em "B" gera maior distribuição da tensão na cúspide lingual do primeiro pré-molar superior.

D) $\mathrm{O}$ valor da intensidade da tensão em torno do limite amelocementário, chega a atingir o dobro do valor da tensão inicial.

\section{Referências}

Brandini, D. A., Trevisan, C. L., Panzarini, S. R., \& Pedrini, D. (2012). Clinical evaluation of the association between noncarious cervical lesions and occlusal forces. The Journal of prosthetic dentistry, 108(5), 298-303. https://doi.org /10.1016/S0022-3913(12)60180-2.

Cerveira Netto, H.; Zanatta, E. (1998) Manual Simplificado de Enceramento Progressivo. São Paulo: Artes Médicas, p. 1-16.

Correia, A., Bresciani, E., Borges, A. B., Pereira, D. M., Maia, L. C., \& Caneppele, T. (2020). Do Tooth- and Cavity-related Aspects of Noncarious Cervical Lesions Affect the Retention of Resin Composite Restorations in Adults? A Systematic Review and Meta-analysis. Operative dentistry, 45(3), E124-E140. https://doi.org/10.2341/19-091-L

Dejak, B., Mlotkowski, A., \& Romanowicz, M. (2005). Finite element analysis of mechanism of cervical lesion formation in simulated molars during mastication and parafunction. The Journal of prosthetic dentistry, 94(6), 520-529. https://doi.org/10.1016/j.prosdent.2005.10.001

El-Anwar, M. I., Yousief, S. A., Soliman, T. A., Saleh, M. M., \& Omar, W. S. (2015). A finite element study on stress distribution of two different attachment Idesigns under implant supported overdenture. The Saudi dental journal, 27(4), 201-207. https://doi.org/10.1016/j.sdentj.2015.03.001

Lanza, A., Aversa, R., Rengo, S., Apicella, D., \& Apicella, A. (2005). 3D FEA of cemented steel, glass and carbon posts in a maxillary incisor. Dental materials: official publication of the Academy of Dental Materials, 21(8), 709-715. https://doi.org/10.1016/j.dental.2004.09.010

Lim, G. E., Son, S. A., Hur, B., \& Park, J. K. (2020). Evaluation of the relationship between non-caries cervical lesions and the tooth and periodontal tissue: An ex-vivo study using micro-computed tomography. PloS one, 15(10), e0240979. https://doi.org/10.1371/journal.pone.0240979

Medeiros, T., Mutran, S., Espinosa, D. G., do Carmo Freitas Faial, K., Pinheiro, H., \& D'Almeida Couto, R. S. (2020). Prevalence and risk indicators of noncarious cervical lesions in male footballers. BMC oral health, 20(1), 215. https://doi.org/10.1186/s12903-020-01200-9 
Research, Society and Development, v. 10, n. 11, e559101119961, 2021

(CC BY 4.0) | ISSN 2525-3409 | DOI: http://dx.doi.org/10.33448/rsd-v10i11.19961

Miller, N., Penaud, J., Ambrosini, P., Bisson-Boutelliez, C., \& Briançon, S. (2003). Analysis of etiologic factors and periodontal conditions involved with 309 abfractions. Journal of clinical periodontology, 30(9), 828-832. https://doi.org/10.1034/j.1600-051x.2003.00378.x

Pai, S., Bhat, V., Patil, V., Naik, N., Awasthi, S., \& Nayak, N. (2020). Numerical Three-dimensional Finite Element Modeling of Cavity Shape and Optimal Material Selection by Analysis of Stress Distribution on Class V Cavities of Mandibular Premolars. Journal of International Society of Preventive \& Community Dentistry, 10(3), 279-285. https://doi.org/10.4103/jispcd.JISPCD_75_20

Reyes, E., Hildebolt, C., Langenwalter, E., \& Miley, D. (2009). Abfractions and attachment loss in teeth with premature contacts in centric relation: clinical observations. Journal of periodontology, 80(12), 1955-1962. https://doi.org/10.1902/jop.2009.090149

Rossi, A. C., Freire, A. R., Ferreira, B. C., Faverani, L. P., Okamoto, R., \& Prado, F. B. (2021). Effects of premature contact in maxillary alveolar bone in rats: relationship between experimental analyses and a micro scale FEA computational simulation study. Clinical oral investigations, 25(9), 5479-5492. https://doi.org/10.1007/s00784-021-03856-1

Silva, N. R., Castro, C. G., Santos-Filho, P. C., Silva, G. R., Campos, R. E., Soares, P. V., \& Soares, C. J. (2009). Influence of different post design and composition on stress distribution in maxillary central incisor: Finite element analysis. Indian journal of dental research: official publication of Indian Society for Dental Research, 20(2), 153-158. https://doi.org/10.4103/0970-9290.52888

Wang, C., \& Yin, X. (2012). Occlusal risk factors associated with temporomandibular disorders in young adults with normal occlusions. Oral surgery, oral medicine, oral pathology and oral radiology, 114(4), 419-423. https://doi.org/10.1016/j.oooo.2011.10.039

Yan, X., Zhang, X., Chi, W., Ai, H., \& Wu, L. (2015). Comparing the influence of crestal cortical bone and sinus floor cortical bone in posterior maxilla bicortical dental implantation: a three-dimensional finite element analysis. Acta odontologica Scandinavica, 73(4), 312-320. https://doi.org/10.3109/00016357.2014.967718 